\title{
Supraphysiological Doses of L-Thyroxine in the Maintenance Treatment of Prophylaxis- Resistant Affective Disorders
}

\author{
Michael Bauer, M.D., Ph.D., Anne Berghöfer, M.D., Tom Bschor, M.D., \\ Andreas Baumgartner, M.D., Ursula Kiesslinger, M.A., Rainer Hellweg, M.D., \\ Mazda Adli, M.D., Christopher Baethge, M.D., and Bruno Müller-Oerlinghausen, M.D.
}

\begin{abstract}
This prospective open-label study examined the efficacy of adjunctive supraphysiological doses of $L$-thyroxine $\left(T_{4}\right)$ in the maintenance treatment of prophylaxis-resistant affective disorder. Twenty-one (16 women, 5 men) of 25 patients enrolled consecutively over an 8-year period on the basis of their status of prophylaxis resistance (defined as two or more failures to standard prophylactic trials) participated for more than four months in the study and were eligible for the intention-to-treat analysis. The mean length of adjunctive treatment with $T_{4}$ was $51.4 \pm 21.7$ months. The mean $T_{4}$ dose at study end was $378.6 \pm 90.2 \mu \mathrm{g} / \mathrm{d}$. The number of episodes and hospitalizations, and the morbidity indices during the time of prophylactic $T_{4}$ treatment, were compared with those measured for the same length of time before the start of $\mathrm{T}_{4}$ treatment (mirror-image method). On the Clinical Global Impression for Bipolar Disorder scale (CGI-BP, Change from Worst Phase of Illness), eleven subjects (52.4\%)
\end{abstract}

were rated as "very much improved", four (19\%) as "much improved", two (9.5\%) as "minimally improved" and four $(19 \%)$ as "no change." The mean total number of recurrences (8.6 before $T_{4}$ treatment vs. 2.8 during $T_{4}$ treatment; $\mathrm{p}=$ .004), the number of hospitalizations (3.1 vs. 1.9; $\mathrm{p}=.026$ ) and the Morbidity Index $\left(\mathrm{MI}_{\text {Total }}=0.71\right.$ vs. $M I_{\text {Total }}=0.28$; $\mathrm{p}<.001)$ significantly declined during $T_{4}$ treatment. Subjects with bipolar disorder $(n=13)$ benefited more from the T4 treatment intervention than did subjects with unipolar major depressive disorder $(n=4)$ and schizoaffective disorder $(n=4)$. In conclusion, adjunctive treatment with L-thyroxine in supraphysiological doses may be an effective strategy in the maintenance treatment of patients with prophylaxis-resistant affective disorders.

[Neuropsychopharmacology 27:620-628, 2002] (C) 2002 American College of Neuropsychopharmacology. Published by Elsevier Science Inc.
KEY WORDS: L-thyroxine; Supraphysiological; Maintenance treatment; Bipolar disorder; Unipolar major depressive disorder; Schizoaffective disorder; Prophylaxis resistance; Augmentation
There is growing recognition that prophylactic treatment of affective disorders may be inadequate in a substantial proportion of patients (Post et al. 1998). Psychiatrists in private practice, as well as in academic referral
From the Department of Psychiatry and Psychotherapy, Charité, Humboldt University of Berlin, Berlin, Germany (MB, UK, MA), Neuropsychiatric Institute \& Hospital, Department of Psychiatry and Biobehavioral Sciences, University of California Los Angeles, Los Angeles, CA (MB), Institute for Social Medicine, Epidemiology and Health Economics, Charité-Hospital, Humboldt University of Berlin, Berlin, Germany (A. Berghöfer), Department of Psychiatry (TB, RH, CB, BM-O), and Nuclear Medicine (Radiochemistry), Freie Universität Berlin, Berlin, Germany (A. Baumgartner).
Address correspondence to: Michael Bauer, M.D., Ph.D., Department of Psychiatry and Psychotherapy, Charité, Humboldt University of Berlin, Schumannstr. 20/21, D-10117 Berlin, Germany. Tel.: (+49) (30) 450-51 70 62; Fax.: (+49) (30) 450-51 79 22; E-mail: michael. bauer@charite.de

Received June 7, 2001; revised November 20, 2001; accepted January 26, 2002.

Online publication: $3 / 5 / 02$ at www.acnp.org/citations/ Npp030502260. 
centers and research settings, increasingly observe patients with mood disorders that respond inadequately to mood stabilizing drugs (Frye et al. 2000). Thus, it is apparent that the development of novel treatment strategies is needed for patients with recurrent affective disorders that do not adequately respond to prophylactic treatment.

One traditional approach for treatment-refractory patients with mood disorders is the supplementation of treatment with thyroid hormone (Prange et al. 1969; Joffe and Sokolov 1994; Bauer and Whybrow 2001). There is evidence from placebo-controlled trials that triiodothyronine $\left(\mathrm{T}_{3}\right)$ may both accelerate (Altshuler et al. 2001) and augment (Joffe et al. 1993; Aronson et al. 1996) the antidepressant response to tricyclic antidepressants. In case reports and in a small-scale open study, supraphysiological doses of L-thyroxine $\left(\mathrm{T}_{4}\right)$ as an adjunctive treatment have been reported as beneficial in treating rapid cycling bipolar disorder (Stancer and Persad 1982; Bauer and Whybrow 1986). However, none of the latter studies focused on long-term outcome, which is a critical issue in the treatment of recurrent mood disorders. This study expanded upon previous studies of adjunctive supraphysiological doses of $\mathrm{T}_{4}$ by investigating its mood-stabilizing efficacy in the maintenance treatment of patients with prophylaxis-resistant affective disorders.

\section{METHODS}

\section{Study Design}

This research was an open prospective maintenance treatment study of the efficacy of adjunctive supraphysiological doses of $T_{4}$ in patients with prophylaxisresistant bipolar and unipolar major depressive and schizoaffective disorders. In this single site study, subjects were enrolled consecutively, based on their status of prophylaxis resistance over an 8-year period (for details see below). The time period was chosen post hoc, based on interim data analysis and the number of subjects enrolled in the study. Subjects were recruited from the Berlin Lithium Clinic (BLC) of the Department of Psychiatry (academic medical center and tertiary care hospital) between July 1989 and August 1998 (called "study end" in the following discussion). The BLC is an outpatient clinic for the long-term treatment of patients with affective disorders. It has a detailed documentation system that includes each patient's history and course of illness, ensuring reliable outcome data of naturalistic treatments. After the procedures were fully explained, written informed consent was obtained from each study participant at the time of enrollment. Preliminary results of the first six subjects were published earlier (Baumgartner et al. 1994).

\section{Subjects}

Both males and females participated in the study and met the following eligibility criteria: (1) age $\geqslant 18$ years; (2) a diagnosis of bipolar disorder, major depressive disorder, recurrent, or schizoaffective disorder according to DSM-III-R criteria (American Psychiatric Association 1987) (in addition, subjects with schizoaffective disorder were only accepted in the study if the patient's history displayed predominantly affective episodes); (3) no response to two or more adequately performed prophylactic treatment trials (including either monotherapy, double combinations, or triple combinations) (for criteria see below); (4) no change in the prophylactic regimen for $\geqslant 3$ months prior to study entry; and (5) an apparent need to change the prophylactic medication regimen, as determined at a clinical case conference attended by a research team member and the treating psychiatrist. Previous prophylactic trials must have been performed for either a minimum duration of six months or a shorter duration when two or more recurrences of mood episodes occurred during adequate treatment. Previous prophylactic treatments were not discontinued after one recurrence due to evidence suggesting that full prophylactic efficacy of lithium may require longer administration. Treatment was considered adequate if the serum levels of the mood stabilizers were in the following ranges: lithium $(\geqslant 0.5 \mathrm{mmol} / \mathrm{L})$, carbamazepine ( $\geqslant 5 \mathrm{mg} / \mathrm{L}$ ), valproate ( $\geqslant 50 \mathrm{mg} / \mathrm{L}$ ). Adequate dosages of antidepressants were: TCA $\geqslant 150$ $\mathrm{mg} / \mathrm{d}$ (75-225 mg/d nortriptyline), SSRIs (fluoxetine, paroxetine, citalopram) $\geqslant 20 \mathrm{mg} / \mathrm{d}$, venlafaxine and fluvoxamine $\geqslant 150 \mathrm{mg} / \mathrm{d}$, tranylcypromine $\geqslant 20 \mathrm{mg} / \mathrm{d}$, and moclobemide $\geqslant 300 \mathrm{mg} / \mathrm{d}$.

The exclusion criteria were: (1) overt (clinical) hypothyroidism; (2) thyroid hormone medication at supraphysiological doses (>150 $\mathrm{\mu g} / \mathrm{d}$ L-thyroxine); (3) conditions considered a contraindication for treatment with supraphysiological $\mathrm{T}_{4}$ doses (history of myocardial infarction, cardiac arrhythmia, severe cardiac insufficiency, previous or current thyroid adenoma, hyperthyroidism); (4) concomitant abuse or dependency of alcohol or addictive drugs; (5) female subjects during pregnancy and breastfeeding; and (6) female subjects within childbearing years who were not using adequate birth control. Subjects were carefully examined for the excluding conditions prior to study entry. The baseline medical evaluation included the following investigations and procedures: physical and neurological examination, consultation with an endocrinologist, reading of vital signs (repeated measurements of blood pressure and pulse), 24-h electrocardiogram (ECG), ergometry, measurement of body weight, various laboratory evaluations (liver enzymes, white and red cell blood count, electrolytes, creatinine) including thyroid function tests (see below) and serum levels of mood stabilizers, and 
additional radiological investigations if clinically indicated (e.g., sonography of the thyroid gland).

A total of 25 subjects fulfilled the inclusion criteria and was consecutively enrolled into the study (for demographic and clinical details see Table 1). Four (16\%) of these 25 subjects were not eligible for the prophylactic outcome analyses because they were in the study for less than four months. They were ineligible for the following reasons: Treatment with $\mathrm{T}_{4}$ was discontinued in one 60-year-old male with bipolar disorder after three months of $\mathrm{T}_{4}$ treatment due to an increase of lithium tremor with subsequent non-compliance. One 33-yearold female patient with schizoaffective disorder was lost for follow-up eight weeks after enrollment; she continued $\mathrm{T}_{4}$ treatment in private practice (no reliable followup data available). One 69-year-old woman with bipolar disorder type II broke her hip shortly after study inclusion; she was treated for this and other medical conditions in other hospitals. $\mathrm{T}_{4}$ treatment was discontinued

Table 1. Demographic and Clinical Characteristics of Patients with Prophylaxis-Resistant Affective Disorders Treated with Supraphysiological Doses of L-Thyroxine $\left(\mathrm{T}_{4}\right)$

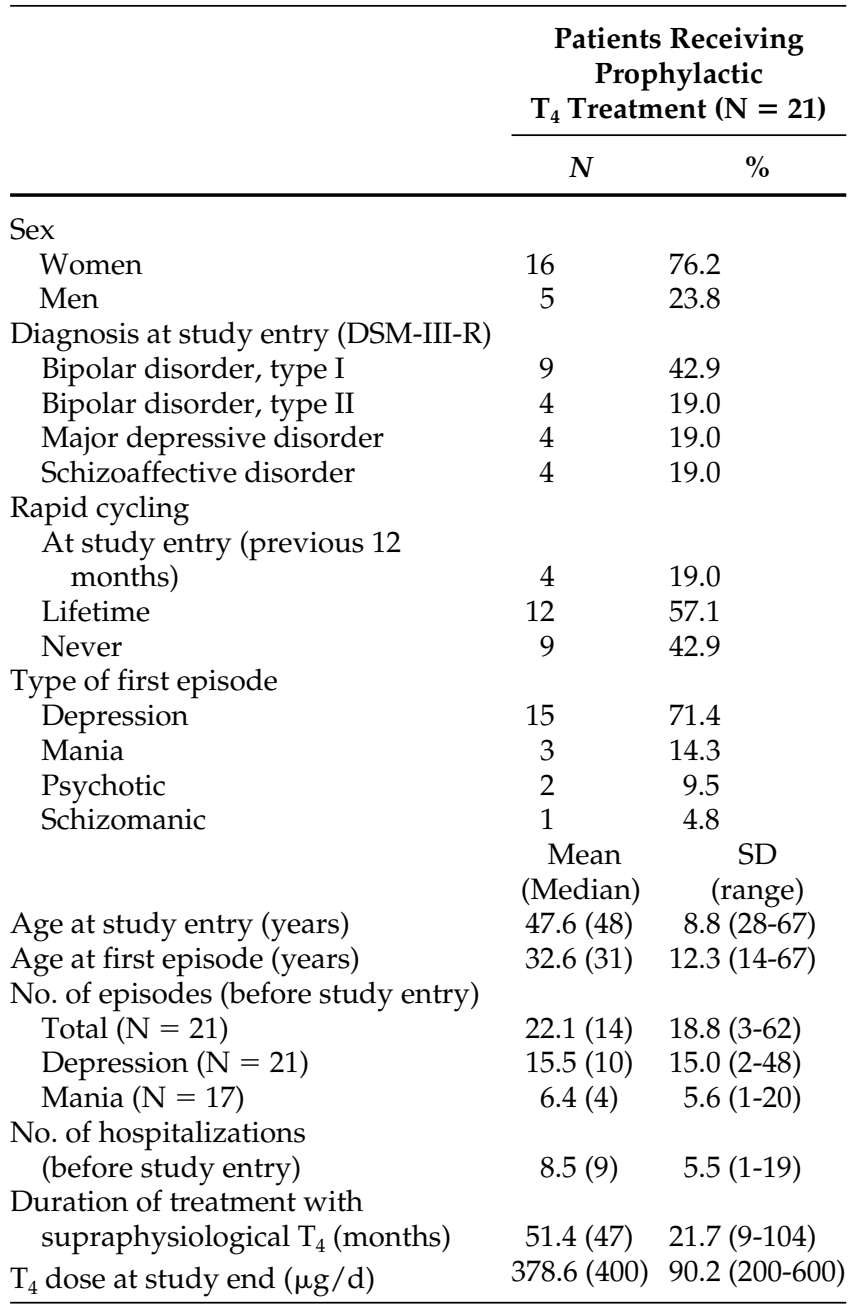

in one 47-year-old female patient because of a diagnostic switch from recurrent major depression to depressive personality disorder 10 weeks after enrollment.

Nineteen $(90 \%)$ of the 21 subjects included in the outcome analysis were in the euthyroid range prior to study entry. Two subjects $(10 \%)$ had thyroid function tests that indicated subclinical hypothyroidism (slightly increased TSH level in one case, decreased $\mathrm{T}_{4}$ levels in the other case, respectively). Four subjects had received replacement doses of $\mathrm{T}_{4}$ prior to study entry for treatment of goiter and lithium-induced hypothyroidism, respectively $(100 \mu \mathrm{g} / \mathrm{d}$ in two cases and $150 \mu \mathrm{g} / \mathrm{d}$ in two cases).

\section{Procedures}

Initiation and Discontinuation of Treatment with L-Thyroxine. Subjects were given $\mathrm{T}_{4}$ in addition to the psychotropic medications they had been receiving during the preceding months. The starting dose was $50 \mu \mathrm{g} \mathrm{T}_{4} /$ $\mathrm{d}$ and thereafter increased by $50 \mu \mathrm{g} / \mathrm{d}$ every three to seven days until a dose of $500 \mu \mathrm{g} / \mathrm{d}$ was reached (but only if the patient tolerated the dose increase). The goal was to achieve TSH suppression and to increase free $\mathrm{T}_{4}$ levels by $\geqslant 50 \%$ compared with the pretreatment level. There were no changes in the prophylactic regimen during the $\mathrm{T}_{4}$ trial (although one patient was switched from carbamazepine to valproate due to an adverse event (decrease of white blood cells); subsequently, this patient's time on valproate was excluded from the outcome analysis). However, if a subject was on multiple medications at study entry and experienced significant clinical improvement during the study, medications not administered for prophylactic purposes could be discontinued to minimize polypharmacy (see Table 2). Acute affective recurrences were treated with antimanic and antidepressant medication, which were terminated within approximately six weeks of remission. The criteria for starting medication interventions for acute episodes were: confirmation of an episode according to DSM-III-R criteria for major depressive episode or manic episode and a score of $\geqslant 15$ on the BechRafaelsen Melancholia Rating Scale (BRMS; Bech and Rafaelsen 1986) (depressive episode) or $\geqslant 10$ on the Bech-Rafaelsen Mania Rating Scale (BRMAS; Bech et al. 1979) (manic episode). These criteria were used throughout the mirror-imaged time periods. The choice of antimanic and antidepressant medications used to treat breakthrough episodes was not operationalized, but prescription patterns did not change significantly before or during the treatment intervention with $\mathrm{T}_{4}$ (see Table 2).

Subjects who did not respond to prophylactic $\mathrm{T}_{4}$ treatment or who wished to stop study participation were withdrawn from $\mathrm{T}_{4}$ treatment gradually (during a 1 to 2 week period). The decision to discontinue a pa- 
Table 2. Comedications of Patients with ProphylaxisResistant Affective Disorders Receiving Supraphysiological Doses of L-Thyroxine $\left(\mathrm{T}_{4}\right)^{\text {a }}$

\begin{tabular}{|c|c|c|c|c|}
\hline & \multicolumn{2}{|c|}{$\begin{array}{c}\text { Before } \mathrm{T}_{4} \\
\text { Treatment } \\
\text { (Baseline) }\end{array}$} & \multicolumn{2}{|c|}{ Study End ${ }^{\mathrm{b}}$} \\
\hline & $n$ & $\%$ & $n$ & $\%$ \\
\hline Lithium & 15 & 71.4 & 14 & 66.7 \\
\hline Carbamazepine & 16 & 76.2 & 13 & 61.9 \\
\hline Valproate & 1 & 4.8 & 2 & 9.5 \\
\hline Antidepressants (total) & 19 & 90.5 & 12 & 57.1 \\
\hline TCA & 14 & 66.7 & 8 & 38.1 \\
\hline SSRI & 3 & 14.3 & 3 & 14.3 \\
\hline MAOI & 2 & 9.5 & 1 & 4.8 \\
\hline Neuroleptics & 10 & 47.6 & 10 & 47.6 \\
\hline Estradiol & 4 & 19.0 & 4 & 19.0 \\
\hline Total number & 65 & & 55 & \\
\hline
\end{tabular}

aPsychotropic agents (mostly given for prophylaxis) and estrogens only

${ }^{b}$ Number of comedications: 1 comedication $(\mathrm{N}=6[28.6 \%]), 2$ comedications $(\mathrm{N}=3[14.3 \%]), 3$ comedications

$(\mathrm{N}=7[33.3 \%]), 4(\mathrm{~N}=3$ each $[14.3 \%])$, and 5 comedications $(\mathrm{N}=2$ $[9.5 \%])$.

tient was made after it became clinically apparent that the $\mathrm{T}_{4}$ medication regimen did not improve or deteriorate the clinical course of the patient's disorder. An attempt was made to continue administration of $\mathrm{T}_{4}$ for at least two years before a definite decision upon discontinuation was made. Clinical and laboratory assessments at study end were performed prior to discontinuation of $\mathrm{T}_{4}$.

\section{Maintenance Treatment with L-Thyroxine}

Subjects were followed-up systematically at the outpatient clinics at intervals ranging from one to 10 weeks, depending on the subject's clinical status. At each or every second visit, safety assessments were performed through laboratory evaluations (thyroid function tests, liver enzymes, white and red cell blood count, electrolytes, creatinine) and vital sign measures (blood pressure, pulse, 12-lead ECG, body weight). Additionally, a cardiological follow-up visit (including physical examination, echocardiography, 24-h ECG and ergometry) and determination of bone mineral density using dual energy X-ray absorptiometry (DEXA) (Gyulai et al. 2001) were performed once per year. Serum levels of mood stabilizers were also monitored before and at each visit during $\mathrm{T}_{4}$ treatment and maintained within the prophylactic ranges. At each visit, a psychiatric clinical interview and a side effect assessment (for details see Bauer et al. 2001) were also performed. If the subjects presented with more than minimal symptoms at the visits, their psychopathological status was assessed with the BRMS and the BRMAS. All medications, recurrences and hospitalizations were carefully documented.
If recurrences occurred, their severity, polarity, and duration were recorded (see below).

\section{Outcome Measures}

Outcome was defined primarily in terms of the recurrence of a major depressive episode or a manic episode, as defined by DSM-III-R criteria. Further outcome variables were the Morbidity Index (MI) and the number of hospitalizations during $\mathrm{T}_{4}$ prophylaxis. These variables were counted/calculated during $\mathrm{T}_{4}$ treatment and were compared with those measured for the same length of time before the start of $\mathrm{T}_{4}$ treatment (mirror-image method) (e.g., if a patient was treated with $\mathrm{T}_{4}$ for 24 months, the number of recurrences during this period was compared with those during the 24 months prior to institution of $\mathrm{T}_{4}$ ). To ensure validity and reliability of clinical ratings and MI determinations, all subjects were treated by one of three psychiatrists throughout the entire study (M.B., A.B., and R.H.). Because all subjects were enrolled from the same outpatient clinic, where they had received long-term psychiatric treatment prior to study entry, the same documentation system (e.g., definition of recurrence, medication side effects, and BRMS/BRMAS rating scales) was used for each subject throughout the mirror-imaged periods for MI determinations. The overall clinical outcome of treatment with $\mathrm{T}_{4}$ was independently assessed at study end by two psychiatrists (M.B. and A.B.). Each subject was assessed using the Clinical Global Impression for Bipolar Disorder (CGI-BP, Change from Worst Phase of Illness; a scale specifically developed and validated for prophylactic ratings, with values ranging from $1=$ very much improved to $7=$ very much worse) (Spearing et al. 1997). The outpatient documentation system, patients' charts, and interviews of each subject were used to rate subjects on the CGI-BP. Results were compared, and differences were discussed and settled by consensus.

\section{Morbidity Index}

Analysis of recurrences was based upon the Morbidity Index (MI) (Coppen and Abou-Saleh 1982), which provides an overall estimate of the prophylactic efficacy of a medication during a distinct time period, if the time period can be compared with the same time period prior to introduction of the medication. Severity of recurrences was characterized by degree " 1 ", " 2 " and " 3 ", with " 1 " referring to mild symptoms (without necessity of additional pharmacological treatment), " 2 " indicating necessity of additional psychotropic medication during outpatient treatment, and " 3 " equaling necessity of inpatient treatment including pharmacological treatment. The duration of episodes was recorded in weeks. The Morbidity Index (MI) for the time (weeks) of prophylactic treatment with $\mathrm{T}_{4}$ was calculated according to 
the following formula: $\mathrm{MI}=(1 \times \mathrm{n}$ weeks $\mathrm{degree} 1+2 \times \mathrm{n}$ weeks $_{\text {degree 2 }}+3 \times n$ weeks degree 3 $_{\text {) }} /$ total observation time in weeks, where $\mathrm{n}$ is the number of weeks at a given severity of recurrences during the total observation time.

The Morbidity Index for the same time period before $\mathrm{T}_{4}$ treatment was calculated similarly. The Morbidity Index (MI) was calculated as a total $\mathrm{MI}\left(\mathrm{MI}_{\text {Total }}\right)$ and for depressive $\left(\mathrm{MI}_{\text {Depression }}\right)$ and manic $\left(\mathrm{MI}_{\text {Mania }}\right)$ episodes separately.

\section{Thyroid Function Tests}

The determination of thyroid hormone levels (total thyroxine $\left(\mathrm{tT}_{4}\right)$, free thyroxine $\left(\mathrm{fT}_{4}\right)$, total triiodothyronine $\left(\mathrm{tT}_{3}\right)$, and free triiodothyronine $\left.\left(\mathrm{fT}_{3}\right)\right)$ and basal thyroidstimulating hormone (TSH) were performed by an endocrine research laboratory, all in duplicate with the following commercially available kits from Henning, Berlin: the IRMA kit for TSH, RIA kits for $\mathrm{T}_{4}$ and $\mathrm{T}_{3}$ and the Dyno-Test for $\mathrm{fT}_{4}$. The normal values determined in the same laboratory were: $\mathrm{tT}_{4} 45-125 \mu \mathrm{g} / \mathrm{L} ; \mathrm{fT}_{4} 7-19$ $\mathrm{ng} / \mathrm{L} ; \mathrm{tT}_{3} 0.8-1.6 \mu \mathrm{g} / \mathrm{L} ; \mathrm{fT}_{3} 2.3-5.1 \mathrm{ng} / \mathrm{L}$; and basal TSH $0.4-3.5 \mathrm{mU} / \mathrm{L}$.

\section{Statistical Analysis}

All subjects who participated in the study for more than four months were included in the intention-to-treat (ITT) population. The Wilcoxon matched pairs test was used to compare outcome measures (morbidity indices, number of episodes and hospitalizations), TSH levels, thyroid hormone levels, vital signs and weight before and during the prophylactic trial with $\mathrm{T}_{4}$. Data were expressed as mean values (with standard deviations (SD, \pm ) and medians, where appropriate). Two-tailed tests were performed throughout the analyses. A nominal level of exact significance $\alpha=0.05$ was accepted.

\section{RESULTS}

Twenty-one subjects (16 women, 5 men; mean age $47.6 \pm$ 8.8 years) with prophylaxis-resistant recurrent disorder (13 bipolar, 4 unipolar, 4 schizoaffective) were included in the ITT analysis (see Table 1 for demographic and clinical characteristics). At the end of this 8-year maintenance study, these subjects had been treated with supraphysiological $\mathrm{T}_{4}$ for an average of $51.4 \pm 21.7$ months (range 9-104). The mean $\mathrm{T}_{4}$ dose at study end was $378.6 \pm$ $90.2 \mu \mathrm{g} / \mathrm{d}$ (see Table 2 for psychotropic comedications).

At study end, eleven subjects (52.4\%) were rated as "very much improved," four (19\%) as "much improved," two (9.5\%) as "minimally improved" and four $(19 \%)$ as "no change" on the CGI-BP, Change from
Worst Phase of Illness (mean score $=1.95 \pm 1.20$, range $=$ 1.0-4.0).

In the ITT group, the total mean number of recurrences ( 8.6 before $\mathrm{T}_{4}$ treatment vs. 2.8 during $\mathrm{T}_{4}$ treatment) ( $p=.004)$ and the number of hospitalizations (3.1 before vs. 1.9 during $\left.\mathrm{T}_{4}\right)(p=.026)$ significantly declined during $\mathrm{T}_{4}$ treatment (Table 3 ). The mean percentage change of episode numbers (before and after $\mathrm{T}_{4}$ treatment) was $-53.4 \pm 62.2$ for all episodes, $-49.1 \pm 67.5$ for depressive episodes and $-56.8 \pm 46.7$ for manic episodes. The Morbidity Index (Total) significantly declined during $\mathrm{T}_{4}$ treatment $\left(\mathrm{MI}_{\text {Total }}=0.71\right.$ before vs. $\mathrm{MI}_{\text {Total }}=$ 0.28 during $\mathrm{T}_{4} ; p<.001$, Wilcoxon test) (Table 3 ).

The number of recurrences and the Morbidity Indices also declined according to individual analysis of the three diagnostic groups (bipolar, unipolar, and schizoaffective). However, due to the small size of each subgroup, these changes were not statistically significant, with exception of the Morbidity Index of the subgroup with bipolar disorder $(p=.021)$ (Table 3).

Thyroid hormone levels (total $\mathrm{T}_{4}$, free $\mathrm{T}_{4}$, total $\mathrm{T}_{3}$, and free $\mathrm{T}_{3}$ ) increased and basal TSH decreased during $\mathrm{T}_{4}$ treatment. These changes in thyroid hormone and TSH levels were statistically significant, except for free T3 levels at study end (Table 4). Both total $\mathrm{T}_{4}$ and free $\mathrm{T}_{4}$ levels increased to a greater extent than did total $\mathrm{T}_{3}$ and free $\mathrm{T}_{3}$ levels during $\mathrm{T}_{4}$ treatment. Both total $\mathrm{T}_{4}$ and free $\mathrm{T}_{4}$ were above the normal levels during $\mathrm{T}_{4}$ treatment. In contrast, total $\mathrm{T}_{3}$ and free $\mathrm{T}_{3}$ levels did not increase above normal levels at study end (see Methods, Table 4).

The mean heart rate (as measured by ECG) increased from $79.6 \pm 10.7$ at baseline to $88.9 \pm 14.8$ after one year of treatment $(p=.078)$, and to $86.8 \pm 13.0$ at study end, respectively $(p=.126)$. Blood pressure and body weight did not change significantly during long-term treatment with $\mathrm{T}_{4}$ (Table 4). Yearly cardiologic follow-up investigations also failed to detect significant changes in the cardiovascular system as measured by echocardiography, 24-h ECG and ergometry (unpublished data).

\section{DISCUSSION}

To our knowledge, this is the first maintenance study investigating the efficacy of adjunctive thyroid hormone in subjects with prophylaxis-resistant affective disorders. Adjunctive treatment of previously prophylaxis-resistant patients with supraphysiological doses of $\mathrm{T}_{4}$ proved successful in a substantial number of patients. The severity of the illness in the population studied is demonstrated by their failure to respond to two or more adequately performed prophylactic trials, the mean duration of illness (15.0 years), the mean number of previous hospitalizations (8.5), and the total mean number of affective episodes (22.1) prior to study entry. Thus, we conclude that supraphysiological doses of $\mathrm{T}_{4}$ 
Table 3. Number of Episodes and Morbidity Indices Before and During Prophylactic Treatment with Supraphysiological Doses of L-Thyroxine $\left(\mathrm{T}_{4}\right)$ in Patients with Prophylaxis-Resistant Affective Disorders (Mirror-Image Method)

\begin{tabular}{|c|c|c|c|c|c|c|}
\hline & \multicolumn{4}{|c|}{ Episodes } & \multirow[b]{3}{*}{$\mathbf{z}$} & \multirow[b]{3}{*}{$p^{\mathrm{b}}$} \\
\hline & \multicolumn{2}{|c|}{ Before $\mathrm{T}_{4}$} & \multicolumn{2}{|c|}{ During $\mathrm{T}_{4}{ }^{\mathrm{a}}$} & & \\
\hline & Mean & SD & Mean & SD & & \\
\hline \multicolumn{7}{|l|}{$\operatorname{ITT} \operatorname{Group}(\mathrm{n}=21)^{\mathrm{c}}$} \\
\hline Total Episodes & 8.6 & 9.8 & 2.8 & 4.2 & -2.75 & .004 \\
\hline Depression $(n=21)$ & 5.8 & 5.9 & 2.4 & 4.2 & -2.50 & .010 \\
\hline Mania $(\mathrm{n}=17)$ & 2.4 & 4.7 & 0.3 & 0.8 & -2.97 & .001 \\
\hline \multicolumn{7}{|l|}{ Bipolar Disorder $(\mathrm{n}=13)$} \\
\hline Total Episodes & 10.0 & 11.7 & 3.9 & 4.9 & -1.85 & .066 \\
\hline \multicolumn{7}{|c|}{ Major Depressive Disorder $(n=4)$} \\
\hline Total Episodes & 4.0 & 2.6 & 0.5 & 0.6 & -1.60 & .250 \\
\hline \multicolumn{7}{|c|}{ Schizoaffective Disorder $(n=4)$} \\
\hline \multirow[t]{4}{*}{ Total Episodes } & 8.7 & 3.5 & 1.5 & 1.7 & -1.60 & .250 \\
\hline & \multicolumn{4}{|c|}{ Morbidity Index (MI) } & & \\
\hline & \multicolumn{2}{|c|}{ Before $\mathrm{T}_{4}$} & \multicolumn{2}{|c|}{ During $\mathrm{T}_{4}{ }^{\mathrm{a}}$} & & \\
\hline & Mean & SD & Mean & SD & $\mathbf{z}$ & $p^{\mathrm{b}}$ \\
\hline \multicolumn{7}{|l|}{ ITT Group $(\mathrm{n}=21)$} \\
\hline $\mathrm{MI}_{\text {Total }}$ & 0.71 & 0.31 & 0.28 & 0.40 & -3.42 & $<.001$ \\
\hline $\operatorname{MI}_{\text {Depression }}(\mathrm{n}=21)$ & 0.58 & 0.36 & 0.26 & 0.40 & -2.91 & .002 \\
\hline $\operatorname{MI}_{\text {Mania }}(\mathrm{n}=17)$ & 0.09 & 0.12 & 0.02 & 0.05 & -2.76 & .003 \\
\hline \multicolumn{7}{|c|}{ MI-Bipolar Disorder $(n=13)$} \\
\hline $\mathrm{MI}_{\text {Total }}$ & 0.70 & 0.38 & 0.34 & 0.45 & -2.30 & .021 \\
\hline \multicolumn{7}{|c|}{ MI-Major Depressive Disorder $(n=4)$} \\
\hline $\mathrm{MI}_{\text {Total }}$ & 0.74 & 0.06 & 0.08 & 0.14 & -1.83 & .125 \\
\hline \multicolumn{7}{|c|}{ MI-Schizoaffective Disorder $(n=4)$} \\
\hline $\mathrm{MI}_{\text {Total }}$ & 0.73 & 0.24 & 0.27 & 0.45 & -1.83 & .125 \\
\hline
\end{tabular}

may be a valuable prophylactic augmentation strategy for severely ill patients with prophylaxis-resistant affective disorders. This conclusion is based on the significant reduction of the number of recurrences (total, depressive and manic) and hospitalizations, as well as the decrease in Morbidity Indices (total, depressive and manic) during $\mathrm{T}_{4}$ treatment. There was no difference worth mentioning in the setting or clinical care that subjects received during the $\mathrm{T}_{4}$ trial compared with the mirror-imaged time prior to the study which could account for the observed effects. None of the subjects underwent formal (specific) psychotherapy during the study.

Our study results, as well as results from previous studies (Stancer and Persad 1982; Bauer and Whybrow 1990; Afflelou et al. 1997), suggest that supraphysiological $\mathrm{T}_{4}$ levels are needed for response. In fact, three of four subjects in this study who had received replacement doses of $\mathrm{T}_{4}(100$ or $150 \mu \mathrm{g} / \mathrm{d})$ for years and still suffered from prophylactic-resistant affective episodes, subsequently responded to the supraphysiological doses of $\mathrm{T}_{4}$, which strongly supports the conclusion that higher doses of $\mathrm{T}_{4}$ are more effective.
The substantial improvement ("very much improved" on the CGI-BP) in $52.4 \%$ of subjects with prophylaxis-resistant disorders suggests the existence of a subgroup that responds favorably to augmentation with supraphysiological $\mathrm{T}_{4}$. Adding those subjects who showed "very much" and "much" improvement on the CGI for prophylactic assessment, the percentage of responders to treatment $(71.4 \%)$ is even higher. We would like to emphasize that six of $21(28.6 \%)$ subjects did not experience more than minimal affective symptomatology during treatment with $\mathrm{T}_{4}$. Similarly, we recently found that a subgroup of subjects with acute therapy-resistant depression also responded considerably to supraphysiological doses of $\mathrm{T}_{4}$ (Bauer et al. 1998). Identifying the predictors of response to this treatment intervention would certainly be valuable to the clinician. However, to date, such predictors remain unknown.

In spite of the increased thyroid hormone blood levels ("hyperthyroxinemia"), the side effects of treatment were reported to be minimal. No severe symptoms of hyperthyroidism or serious adverse events were observed, even after treatment with supraphysiological 
Table 4. Thyroid Function Tests, Vital Signs and Body Weight Before and During Treatment with Supraphysiological L-Thyroxine $\left(\mathrm{T}_{4}\right)$ in Prophylaxis-Resistant Affective Disorders

\begin{tabular}{|c|c|c|c|c|c|c|}
\hline & \multicolumn{2}{|c|}{$\begin{array}{c}\text { Before } \mathrm{T}_{4} \text { Treatment } \\
\text { (Baseline) } \\
\mathrm{n}=21\end{array}$} & \multicolumn{2}{|c|}{$\begin{array}{c}\text { During } \mathrm{T}_{4} \text { Treatment } \\
(1 \text { year) } \\
n=21\end{array}$} & \multicolumn{2}{|c|}{$\begin{array}{c}\text { Study End a } \\
n=21\end{array}$} \\
\hline & Mean & SD & Mean & SD & Mean & SD \\
\hline $\begin{array}{l}\text { Total thyroxine }\left(\mathrm{tT}_{4}\right) \\
\text { (normal range: } 45-125 \mu \mathrm{g} / \mathrm{L} \text { ) }\end{array}$ & 73.14 & 16.49 & $152.53^{b}$ & 37.75 & $162.50^{b}$ & 36.78 \\
\hline $\begin{array}{l}\text { Free thyroxine }\left(\mathrm{fT}_{4}\right) \\
\text { (normal range: } 7-19 \mathrm{ng} / \mathrm{L} \text { ) }\end{array}$ & 9.97 & 3.49 & $27.64^{\mathrm{b}}$ & 10.32 & $26.36^{b}$ & 8.07 \\
\hline $\begin{array}{l}\text { Total triiodothyronine }\left(\mathrm{tT}_{3}\right) \\
\text { (normal range: } 0.8-1.6 \mu \mathrm{g} / \mathrm{L} \text { ) }\end{array}$ & 1.05 & 0.30 & $1.63^{\mathrm{c}}$ & 0.42 & $1.41^{\mathrm{c}}$ & 0.26 \\
\hline $\begin{array}{l}\text { Free triiodothyronine }\left(\mathrm{fT}_{3} \text { ) }\right. \\
\text { (normal range: } 2.3-5.1 \mathrm{ng} / \mathrm{L} \text { ) }\end{array}$ & 3.72 & 1.05 & $4.77^{\mathrm{c}}$ & 1.20 & $4.34^{\mathrm{d}}$ & 1.32 \\
\hline $\begin{array}{l}\text { TSH basal } \\
\text { (normal range: } 0.4-3.5 \mathrm{mU} / \mathrm{L} \text { ) }\end{array}$ & 1.66 & 1.16 & $0.07^{b}$ & 0.09 & $0.06^{\mathrm{b}}$ & 0.06 \\
\hline Heart rate (beats/min) & 79.6 & 10.7 & $88.9^{\mathrm{d}}$ & 14.8 & $86.8^{\mathrm{d}}$ & 13.0 \\
\hline $\begin{array}{l}\text { Blood pressure (mm HG) } \\
\text { Systolic }\end{array}$ & 125.0 & 14.1 & $119.5^{\mathrm{d}}$ & 14.9 & $126.2^{d}$ & 15.1 \\
\hline $\begin{array}{l}\text { Blood pressure (mm HG) } \\
\text { Diastolic }\end{array}$ & 78.8 & 8.9 & $79.8^{d}$ & 7.0 & $77.6^{d}$ & 8.9 \\
\hline Body weight $(\mathrm{kg})$ & 73.9 & 16.0 & $74.4^{\mathrm{d}}$ & 16.6 & $74.0^{\mathrm{d}}$ & 16.4 \\
\hline
\end{tabular}

doses of $\mathrm{T}_{4}$ over a period of several years (for details on subjective tolerability and side effects see Bauer et al. 2001). The only case of early discontinuation due to side effects was one in which the patient's lithium tremor increased after $\mathrm{T}_{4}$ was administered. The underlying mechanism behind the good tolerability of supraphysiological doses of $\mathrm{T}_{4}$ in patients with affective disorders is unknown. The low rate of side effects contrasts with what is typically seen in patients with primary thyroid disorders and healthy controls treated with higher than replacement doses of $\mathrm{T}_{4}$ (Bauer et al. 2002a).

Although the mean duration of treatment with $\mathrm{T}_{4}$ was more than four years, the side effects of treatment with supraphysiological doses of $\mathrm{T}_{4}$ beyond the time assessed in this study are unknown. With respect to bone demineralization, two studies of premenopausal and postmenopausal women with bipolar disorder demonstrated no clinically significant loss of bone mineral density (BMD) during long-term treatment with $\mathrm{T}_{4}$ (mostly at supraphysiological doses), but did underscore the need for regular (once per year) assessment of BMD in postmenopausal women (Gyulai et al. 1997, 2001; Bauer et al. 2002c). The long-term effects on the cardiovascular system remain to be objectively studied. Nonetheless, we continue to recommend that adjunctive supraphysiological doses of $\mathrm{T}_{4}$ be reserved for the maintenance treatment of patients with the most refractory of affective disorders.

Interpretation of these results has some clear limitations. Due to the open design, no blinded ratings were performed. Subjects who dropped out very early $(<4$ months) ( $16 \%$ of the enrolled study group) were excluded from the outcome analysis. This could be a bias in favor of the results. Also, some characteristics of the study group could limit generalizability of the results. First, subjects were enrolled from a specialized outpatient clinic where they have received medical care for many years. Patients from such specialized outpatient clinics are typically highly compliant. However, a high rate of compliance may also be due to favorable subjective response and good tolerability of treatment with L-thyroxine medication as reported by the subjects (Bauer et al. 2001). A second consideration is that a high percentage $(76 \%)$ of the subjects included in the ITT analysis were females. Third, different diagnostic groups were enrolled.

With respect to the lack of a control group in this study, we would like to emphasize that including a placebo arm to a group of severely ill patients who are resistant to prophylactic medications was not possible due to human subject guidelines at our institution. Although we admit that including an active control group in a randomized trial would have been a reasonable option for an alternative study design, selecting an adequate active control medication would have been difficult. The majority of subjects enrolled into this study belonged to the most severely ill patients at our department who were resistant to most prophylactic medications available at the time of the study. Furthermore, 
we would like to stress that there was little published data on the treatment with $\mathrm{T}_{4}$ in supraphysiological doses at the time of study initiation.

Among the strengths of the study are the long follow-up period (on average subjects were in the study for more than four years) and the relatively large number of subjects with prophylaxis-resistant affective disorders. Other strengths of the study are the rigorous definition of prophylaxis resistance and the precise documentation of various relevant descriptive variables (e.g., subjects' long-term course of illness, including medications before and during the study). Obtaining long-term course of illness information was only possible within the special setting provided by the research outpatient clinic that specializes in long-term treatment of patients with affective disorders.

The molecular and neurochemical actions of thyroid hormones in the adult brain that underlie its mood modulating properties in affective illness are currently unknown (Baumgartner 2000, Bauer and Whybrow 2001). The influence of the thyroid system on neurotransmitters that putatively play a major role in the regulation of mood and behavior, serotonin and norepinephrine, may contribute to the mechanisms of thyroid hormone action (Henley and Koehnle 1997; Bauer et al. 2002b). Clinical studies may provide a better understanding of the mood stabilizing effects of $\mathrm{T}_{4}$ given at supraphysiological doses. The evaluation of thyroid indices in lithium-maintained patients with mood disorders has shown an association between decreased serum $\mathrm{T}_{3}$ levels and recurrences (Hatterer et al. 1988; Baumgartner et al. 1995). A low level of free $\mathrm{T}_{4}$ was also associated with more affective episodes and greater severity of depression during prophylactic lithium treatment in patients with bipolar disorder (Frye et al. 1999). Thus, it appears that higher free $\mathrm{T}_{4}$ and higher $\mathrm{T}_{3}$ levels are advantageous for long-term lithium treatment, a finding that would be consistent with the efficacy of treatment with supraphysiological $\mathrm{T}_{4}$, as this intervention significantly increases the free $T_{4}$ and $T_{3}$ levels. Also of interest are findings of significantly lower CSF transthyretin (TTR) levels in refractory depressed subjects (Hatterer et al. 1993) and in drug-free subjects with non-refractory depression compared with healthy controls (Sullivan et al. 1999). Reduced levels of TTR in the brain might disrupt delivery of thyroid hormones to regions inside the blood-brain barrier, despite functioning of thyroid hormone feedback to the hypothalamus and pituitary to maintain peripheral hormone levels. It was hypothesized that a lack of TTR might account for "brain hypothyroidism" with normal peripheral (serum) thyroid hormone concentration in depression, and thus contribute to failed response to standard antidepressive treatment (Sullivan et al. 1999). It may be speculated that such a disrupted delivery of $\mathrm{T}_{4}$ to the brain might contribute to the pathophysiological mechanisms in affective illness.

\section{CONCLUSIONS}

Adjunctive treatment with L-thyroxine in supraphysiological doses may be an effective and well-tolerated strategy in the maintenance treatment of patients with prophylaxis-resistant affective disorders. In this open study, a substantial number of severely ill and prophylaxis-resistant patients did experience full remission from affective symptomatology during this treatment intervention. Thus, additional research using a more rigorous scientific design (e.g., including an active comparator or a placebo group) is warranted.

\section{ACKNOWLEDGMENTS}

This study was supported by a grant from the Deutsche Forschungsgemeinschaft (\# Ba 1504/3-1) and a Judson Braun Research Scholarship form the UCLA Neuropsychiatric Institute to M.B. We thank Gunnar Berghöfer, M.D., for performing the cardiological follow-up visits, Professor Klaus-Jürgen Graef, M.D., for endocrine consultations, and Trina Haselrig, M.A., for editorial assistance.

In part presented at the Second International Congress on Hormones, Brain and Neuropsychopharmacology. Rhodes, Greece, July 15-19, 2000.

\section{REFERENCES}

Afflelou S, Auriacombe M, Cazenave M, Chartres JP, Tignol J (1997): Administration of high dose levothyroxine in treatment of rapid cycling bipolar disorders. Review of the literature and initial therapeutic application apropos of 6 cases [Article in French]. Encephale 23:209-217

Altshuler LL, Bauer M, Frye MA, Gitlin MJ, Mintz J, Szuba MP, Leight KL, Whybrow PC (2001): Does thyroid supplementation accelerate antidepressant response? A review and meta-analysis of the literature. Am J Psychiatry 158:1617-1622

American Psychiatric Association (1987): Diagnostic and statistical manual of mental disorders, $3^{\text {rd }}$ ed. rev. DSM-III-R. Washington, DC, American Psychiatric Association

Aronson R, Offman HJ, Joffe RT, Naylor D (1996): Triiodothyronine augmentation in the treatment of refractory depression. A meta-analysis. Arch Gen Psychiatry 53: 842-848

Bauer M, Baur H, Berghöfer A, Ströhle A, Hellweg R, MüllerOerlinghausen B, Baumgartner A (2002a): Effects of supraphysiological thyroxine administration in healthy controls and patients with depressive disorders. J Affect Disord (in press)

Bauer M, Fairbanks L, Berghöfer A, Hierholzer J, Bschor T, Baethge C, Rasgon N, Whybrow PC (2002c): No evidence of accelerated bone density loss during mainte- 
nance treatment with supraphysiological doses of L-thyroxine in affective disorders (submitted)

Bauer M, Heinz A, Whybrow PC (2002b): Thyroid hormones, serotonin and mood: of synergy and significance in the adult brain. Mol Psychiatry 7:140-156

Bauer M, Hellweg R, Gräf KJ, Baumgartner A (1998): Treatment of refractory depression with high-dose thyroxine. Neuropsychopharmacology 18:444-455

Bauer M, Priebe S, Berghöfer A, Bschor T, Kiesslinger K, Whybrow PC (2001): Subjective response to and tolerability of long-term supraphysiological doses of levothyroxine in refractory mood disorders. J Affect Disord 64:35-42

Bauer M, Whybrow PC (2001): Thyroid hormone, neural tissue and mood modulation. World J Biol Psychiatry 2: $57-67$

Bauer MS, Whybrow PC (1986): The effect of changing thyroid function on cyclic affective illness in a human subject. Am J Psychiatry 143:633-636

Bauer MS, Whybrow PC (1990): Rapid cycling bipolar affective disorders. II. Treatment of refractory rapid cycling with high-dose levothyroxine: a preliminary study. Arch Gen Psychiatry 47:435-440

Baumgartner A (2000): Thyroxine and the treatment of affective disorders: an overview of the results of basic and clinical research. Int J Neuropsychopharmacol 3:149-165

Baumgartner A, Bauer M, Hellweg R (1994): Treatment of intractable non-rapid cycling bipolar affective disorder with high-dose thyroxine: an open clinical trial. Neuropsychopharmacology 10:183-189

Baumgartner A, von Stuckrad M, Müller-Oerlinghausen B, Gräf KJ, Kürten I (1995): The hypothalamic-pituitarythyroid axis in patients maintained on lithium prophylaxis for years: high triiodothyronine serum concentrations are correlated to the prophylactic efficacy. J Affect Disord 34:211-218

Bech P, Bolwig TG, Kramp P, Rafaelsen OJ (1979): The BechRafaelsen Mania Scale and the Hamilton Depression Scale: evaluation of homogeneity and inter-observer reliability. Acta Psychiatr Scand 59:420-430

Bech P, Rafaelsen OJ (1986): The melancholia scale: Development, consistency, validity and utility. In Sartorius N, Ban PA (eds), Assessment of Depression. Berlin, Springer, pp 259-269

Coppen A, Abou-Saleh MT (1982): Plasma folate and affective morbidity during long-term lithium therapy. Br J Psychiatry 141:87-89

Frye MA, Denicoff KD, Bryan AL, Smith-Jackson EE, Ali SO, Luckenbaugh D, Leverich GS, Post RM (1999): Association between lower serum free $\mathrm{T} 4$ and greater mood instability and depression in lithium-maintained bipolar patients. Am J Psychiatry 156:1909-1914

Frye MA, Ketter TA, Leverich GS, Huggins T, Lantz C, Denicoff KD, Post RM (2000): The increasing use of polypharmacotherapy for refractory mood disorders: 22 years of study. J Clin Psychiatry 61:9-15

Gyulai L, Bauer M, Espana-Garcia F, Hierholzer J, Baumgartner A, Whybrow PC (2001): Bone mineral density in pre- and post-menopausal women with affective disorder treated with long-term L-thyroxine augmentation. J Affect Disord 66:185-191

Gyulai L, Whybrow PC, Jaggi J, Bauer MS, Younkin S, Rubin L, Attie M (1997): Bone mineral density and L-thyroxine treatment in rapidly cycling bipolar disorder. Biol Psychiatry 41:503-506

Hatterer JA, Herbert J, Hidaka C, Roose SP, Gorman JM (1993): CSF transthyretin in patients with depression. Am J Psychiatry 150:813-815

Hatterer JA, Kocsis JH, Stokes PE (1988): Thyroid function in patients maintained on lithium. Psychiatry Res 26:249-257

Henley WN, Koehnle TJ (1997): Thyroid hormones and the treatment of depression: An examination of basic hormonal actions in the mature mammalian brain. Synapse 27:36-44

Joffe RT, Singer W, Levitt AJ, MacDonald C (1993): A placebo-controlled comparison of lithium and triiodothyronine augmentation of tricyclic antidepressants in unipolar refractory depression. Arch Gen Psychiatry 50: 387-393

Joffe RT, Sokolov STH (1994): Thyroid hormones, the brain, and affective disorders. Crit Rev Neurobiol 8:45-63

Post RM, Frye MA, Denicoff KD, Leverich GS, Kimbrell TA, Dunn RT (1998): Beyond lithium in the treatment of bipolar illness. Neuropsychopharmacology 19:206-219

Prange AJ Jr, Wilson IC, Rabon AM, Lipton MA (1969): Enhancement of imipramine antidepressant activity by thyroid hormone. Am J Psychiatry 126:457-469

Spearing MK, Post RM, Leverich GS, Brandt D, Nolen W (1997): Modification of the Clinical Global Impressions (CGI) Scale for use in bipolar illness (BP): the CGI-BP. Psychiatry Res 73:159-171

Stancer HC, Persad E (1982): Treatment of intractable rapidcycling manic-depressive disorder with levothyroxine. Arch Gen Psychiatry 39:311-312

Sullivan GM, Hatterer JA, Herbert J, Chen X, Roose SP, Attia E, Mann JJ, Marangell LB, Goetz RR, Gorman JM (1999): Low levels of transthyretin in the CSF of depressed patients. Am J Psychiatry 156:710-715 